\title{
China's Annual Turnover of “Double Eleven Global Carnival” after COVID-19
}

\author{
Yidou Fan $^{1, *}$ \\ ${ }^{1}$ Bishop Ready High School, Columbus, USA \\ * Correspondence: fanyidou0308@163.com
}

(Received: 12/26/2020; Accepted: 01/11/2021; Published: 01/13/2021)

DOI: https://doi.org/10.37906/isteamc.2021.2

\begin{abstract}
The annual Double Eleven Global Carnival came to an end not long ago. Although the Double Eleven has just been founded for 11 years, it has become one of the most influential projects in the world with its amazing total sales and sales speed and its amazing influences. For 2020, compared with previous years, whether from the perspective of customer demand or the cash flow of the business itself, it seems to be unfavorable to the sales of Double Eleven. But unexpectedly, even though the economy of many enterprises in many countries has stagnated due to the pandemic, the volume of business this year has increased significantly. Moreover, the Double Eleven continued the style of previous years. It continued to expand overseas markets, and achieved win-win situation while cooperating with other countries. In fact, there are many factors behind such a seemingly strange phenomenon.
\end{abstract}

Keywords: Double Eleven; Global pandemic; Live broadcast

As the most influential project ranked sixth in the world by a US company in 2019, the Double Eleven Global Carnival has attracted much attention in the context of the global pandemic in 2020. Before it officially started, some people were not optimistic about the sales of Double Eleven, but on the contrary, the final sales were beyond many people's expectation. The global pandemic not only stimulated people's consumption, but also led to the rise of the live broadcasting industry. It also helped businesses to create a new shopping mode. People gradually became accustomed to and relied on shopping with the stars and bloggers in the live room, bringing a totally new shopping experience to customers. In addition, the clever use of pre-sale helps businesses to effectively grasp the consumer demand of customers and adjust the plan in time, which created more possibilities for the enterprises that originally did not have hope to achieve their annual sales target. At the same time, the Double Eleven Global Carnival has been recognized by more countries and cooperated with them. Therefore, the best explanation for the Double Eleven Shopping Festival in 2020 is to help China and other countries jointly recover the economy after the global pandemic.

Over the past decades, with the rise of e-commerce, China's annual turnover of "Double Eleven Global Carnival" (Double Eleven is a promotion started in 2009 by Taobao Mall) is growing at a doubling rate. During this consumption festival, online and even offline shopping malls always choose to discount many products to attract customers. The two important reasons why such an annual special festival has been getting better and better from 2009 to now are the consumer demand of customers and the main promotion mode constantly changing every year. As the largest consumption Festival after the pandemic, Double Eleven Global Carnival in 2020 has always attracted much attention. Before the official launch of the double eleven event this year, many people are worried that the sales of the double eleven will not be very considerable. However, what is shocking is that the transaction volume of Taobao live broadcast has exceeded the sales volume of one day in last year just ten minutes after the pre-sale started on October 21. 
After reading the exciting introduction, most people would like to ask: How did such rapid sales come from in this special year?

This seems to be a strange phenomenon, but in fact, there are other factors leading to such amazing sales.

Compared with previous years, the most special point of the "Double Eleven" in 2020 is that each ecommerce platform greatly uses the way of online celebrities and stars selling goods in the live broadcasting room to promote sales. Live broadcasting industry cannot do without the power of the pandemic. If we go back to 2019, we find that in 2019, live broadcasting is still a new thing and has not yet been popularized among the public. The ultimate popularity of this industry has experienced from the beginning of invention to a series of development and also the boost of pandemic situation. During the pandemic which people cannot go out for entertainment, more and more people who didn't like to watch live broadcast before began to enjoy that in their leisure time. As a consequence, in just one year from 2019 to 2020, the rise of the live broadcasting industry created the birth of countless webcast anchors and in this way, people are becoming much more familiar with and believing in the good things recommended by these anchors.

This year, when the Double Eleven was just launched, hundreds of millions of people visited Taobao live broadcasting room. Such amazing data totally comes from the popularity and acceptance of the live broadcasting industry. This can be best illustrated by one of the best sales anchors in double eleven festival named Li Jiaqi. In one of his live broadcast in Double Eleven Carnival, 160 million people watched it and the total transaction amount on that day was as high as RMB 3.87 billion. Through highquality content output and countless efforts, he has become extremely popular today and has a place in the sales volume of Double Eleven. In addition to the live bloggers appeared in the studio, more than 300 stars have entered the studio to interact with the audience. Such a series of activities not only improve the commercial value of stars, but also give customers a richer shopping experience.

At the same time, the rapid development of the live broadcasting industry brought to China by the pandemic also attracted the attention of many foreign leaders. After all, China is a place that can be called a huge market even in the world, so many countries chose to cooperate with China. In June this year, 10 ambassadors from central and Eastern European countries, including Slovenia and Hungary, participated in a live broadcast to introduce their local products to Chinese buyers, which attracted hundreds of millions of people in a short time. This is not only a live broadcast, but also the best proof of win-win cooperation and economic recovery. I remember Kevin Aloca, YouTube's pop trend manager, once said, "creating interaction can create trends". It is due to the rise of the live broadcast industry and the continuous improvement of this emerging industry, which brings consumers a new shopping experience. Through the interaction between consumers and anchors, it has successfully led to a wave of shopping trend following the anchor's recommendation.

In addition to the way of selling goods by anchors, of course, the duration changes of the 2020 Double Eleven Festival has also become a major bright spot which also provides a guarantee for the sales of the Double Eleven after the pandemic. Due to the impact of the global pandemic situation, many industries were still in the state of economic stagnation or slow recovery at that time. In this case, if the businesses want to grasp the needs of customers deeply, they must make a prediction before the official sale. After all, customers' demand for goods is the key factor to determine the sales volume to a large extent.

For some industries, businesses can predict people's consumption demand early and make preparations in advance. For example, in the first half of 2020, many families' marriage plans and new house decoration plans were put off reluctantly. Therefore, the number of people who need to buy wedding supplies and furniture will naturally increase sharply in the second half of 2020. As expected, even just on the day of the Double Eleven, Suning kitchen and bathroom home decoration orders 
increased by $138 \%$ year-on-year, and the turnover of Jingdong household products increased by more than $300 \%$ in the first ten minutes of November 1st. These vivid data are the best proof.

But for some other industries, it is difficult for businesses to deeply grasp the demand trend of customers, so they need to prepare in other ways. This is one of the reasons why this year's "double 11" lasted for 22 days. These 22 days, which from October 21 to November 11, was divided into two waves of sales: pre-sale and formal opening. Pre-sale means that the consumer first pays the deposit according to the deposit proportion set by the seller, and then pays the balance according to the pre-sale time period set by the seller, and then the seller delivers the goods. But if the consumer cannot pay according to the payment time set by the seller, the deposit will not be returned.

However, such a change in duration is not only to understand the needs of customers. It can be found from the data that in recent years, various e-commerce platforms are extending the time line of "Double Eleven", because they found that when the double eleven lasted for a short time, people were prone to impulsive consumption. After experiencing such a lesson, more and more rational consumers really need longer time to consider and measure. Therefore, the Double Eleven Global Carnival is like a marathon race, from pre-sale to formal opening, although the time front line is very long, businesses can actually harvest more considerable profits and returns. At the same time, it should not be ignored that the extension of the festival period not only reduces the concentration pressure of logistics, but also gives more enterprises, especially the small and medium-sized enterprises affected by the pandemic situation, with sufficient opportunities for exhibition and sales. Because in the context of the global pandemic in 2020, many enterprises' annual sales are not up to the target, so the double eleven festival naturally become a good opportunity for them to achieve their annual target. In a recent report, a reporter learned from an interview with the person in charge of e-commerce operation of a small household appliance enterprise that they knew more accurately about the future sales situation through pre-sale in the "double eleven" of this year. In this way, they successfully analyzed and grasped these data, and then react to the supply chain, so as to achieve higher profit effect.

Double Eleven Global Carnival of 2020 has finished perfectly and achieved very good total sales. If we take Tmall with the best data as an example, we can know that the final turnover of Tmall during Double Eleven in 2020 is RMB 498.2 billion, while the final turnover of Tmall in 2019 is RMB 268.4 billion, and the final turnover of Tmall in 2018 is RMB 213.5 billion. Therefore, both from the intuitive figures and the hidden growth rate, the Double Eleven of 2020 has achieved a difficult breakthrough.

Furthermore, the Double Eleven Festival also gained good profits in the overseas market. In the whole world, the Double Eleven has its unique influence as early as 2019. Previously, a US media company selected the 50 most influential projects in the world, and the Double Eleven from China ranked sixth. Also, foreign media pointed out in the selection: "it has fundamentally changed the way people shop and opened the boundary between shopping and entertainment". The top five projects are the Internet, Apollo moon landing, Intel 4004 microprocessor, euro and human genome project. Together with these weight level projects, the influence of Double Eleven is self-evident. Even after the global pandemic, the Double Eleven in 2020 still did not fall behind. Before the shopping festival, Alibaba ecommerce platform announced that the Double Eleven exhibition has products from more than 220 countries and regions, which is enough to show the interest and support of other countries for the Double Eleven Festival. For example, German car brand Porsche set up their Tmall store, and Swiss watch brand Vacheron Constantin also released its latest products on this year's "Double Eleven". Meanwhile, despite travel bans, many international stars, including pop star Katy Perry, even attended the festival online.

Therefore, Double Eleven has become a global shopping festival, which not only helped China, but also helped countries around the world to recover their economy after the pandemic. 
This sudden global pandemic has led to changes in many areas in the past year. However, although the pandemic has brought great harm to the vast majority of fields, there is no doubt that the pandemic has virtually promoted the rise of the live broadcasting industry, bringing a lot of things that people would not have chosen to buy online into the live broadcasting room, which helped people get used to and began to rely on buying things from the live broadcasting room at the pace of the anchors. The rise of the shopping trend and the lengthening of the time line in the live broadcasting room have brought a turning point to the "Double Eleven" shopping festival, which was not expected to be optimistic. At the same time, it has also brought opportunities for businesses in different industries to turn losses into profits.

In addition, the further expansion of overseas markets is also the highlight of the "Double Eleven" shopping festival in 2020. In the case that the economic situation after the pandemic is not optimistic, the "Double Eleven" festival has not only helped China recover its economy, but also played a role in boosting the economic recovery of other countries.

\section{References:}

Hongbing L. (October 28, 2013). The origin and development of Double Eleven. Retrieved from http://abc.wm23.com/luhongbin/274322.html

The origin of double eleven. Wikipedia. (November 20th, 2020). Retrieved from https://zh.wikipedia.org/wiki/\%E5\%8F\%8C\%E5\%8D\%81\%E4\%B8\%80

Li Jiaqi sells 3.8 billion goods live, with a monthly salary of 6000 to 600 million a night: people who can speak are closer to success: Tencent News client we media. Retrieved from https://new.qq.com/omn/20201106/20201106A0A2QU00.html

Features of live broadcast activities: Baidu Wikipedia. Retrieved from https://baike.baidu.com/item/2020\%E5\%8F\%8C\%E5\%8D\%81\%E4\%B8\%80\%E8\%B4\%AD\%E7\%89\% A9\%E7\%8B $\% 82 \% \mathrm{E} 6 \% \mathrm{AC} \% \mathrm{~A} 2 \% \mathrm{E} 8 \% 8 \mathrm{~A} \% 82 / 53955002$

A day's turnover is 20 billion. How does the anchor of the seller do it, Kevin Alloca, Swipe the screen: Crazy rules in the video age: Official account number of CITIC Publishing Group.(November 22, 2019). Retrieved from https:/ / baijiahao.baidu.com/s?id=1650906255136065970\&wfr=spider\&for $=p c$

Analysis report on Double Eleven sales data of the whole network in 2020: Global enterprise trends (November 17th, 2020). Retrieved from https://xw.qq.com/amphtml/20201117A0137R00

Jingjing Y., Shanxi Securities Co., Ltd (November 13th, 2020): Sales volume of furniture and building materials. Retrieved from https://stock.finance.sina.com.cn/stock/go.php/vReport Show/kind/industry/rptid/658588438139/in dex.phtml

Shen Z., Xi L., Qiman S, and Yangcheng Evening News (October 29, 2020): What are the new ways to open the first "double eleven" under the influence of the epidemic? Retrieved from http://www.gd.xinhuanet.com/newscenter/2020-10/29/c 1126670632.htm

Beichen L., Sina Finance: Turnover of Tmall during Double Eleven in 2020. Retrieved from https://finance.sina.com.cn/chanjing/gsnews/2020-11-12/doc-iiznezxs1358721.shtml 
Shaoming L. (November 8th, 2019): Sales statistics of Double Eleven in 2019. Retrieved from https:/pcedu.pconline.com.cn/1299/12996432.html

Shaoming L. (November 9th, 2018): Sales statistics of Double Eleven in 2018. Retrieved from https://pcedu.pconline.com.cn/1195/11956046.html

Xianmei Li (November 3rd, 2017): Sales statistics of Double Eleven in 2017. Retrieved from https://pcedu.pconline.com.cn/1023/10232364.html

Sina Finance(October 16th, 2019): Tmall Double Eleven ranked the sixth most influential project in the world by American project management magazine. Retrieved from https://finance.sina.com.cn/stock/usstock/c/2019-10-16/doc-iicezuev2618983.shtml

Jie K., People's Daily Online (November 12, 2020): Double Eleven shopping festival brings in new features to offset pandemic impact. Retrieved from http://en.people.cn/n3/2020/1112/c90000-9779381.html 